BULLETIN Bulletin hispanique

HISPANIQUE Université Michel de Montaigne Bordeaux

118-2 | 2016

Varia

\title{
La revista Índice, de Juan Ramón Jiménez
}

ideación y ensayo preliminar del 27

Ángel L. Prieto de Paula

CpenEdition

Journals

Edición electrónica

URL: http://journals.openedition.org/bulletinhispanique/4551

DOI: 10.4000/bulletinhispanique.4551

ISSN: 1775-3821

Editor

Presses universitaires de Bordeaux

Edición impresa

Fecha de publicación: 15 diciembre 2016

Paginación: 555-572

ISBN: 979-10-300-0125-9

ISSN: 0007-4640

Referencia electrónica

Ángel L. Prieto de Paula, «La revista Índice, de Juan Ramón Jiménez », Bulletin hispanique [En línea],

118-2 | 2016, Publicado el 15 diciembre 2019, consultado el 31 diciembre 2019. URL : http://

journals.openedition.org/bulletinhispanique/4551 ; DOI : 10.4000/bulletinhispanique.4551

Tous droits réservés 


\title{
La revista Índice, de Juan Ramón Jiménez: ideación y ensayo preliminar del 27
}

\author{
Ángel L. Prieto de Paula \\ Universidad de Alicante
}

A la memoria de Nigel Dennis

Le présent article montre l'influence qu'a exercée, sur la formation des auteurs de la Génération de 27, Indice (1921-1922), revue de " poésie nouvelle " fondée par Juan Ramón Jiménez. Des auteurs comme Pedro Salinas, Jorge Guillén, Gerardo Diego, García Lorca, encore inédités à l'époque et totalement inconnus pour la plupart, ont publié dans les quatre numéros de la revue. Quelques années avant le centenaire de Góngora en 1927, c'est donc dans ses pages que ces auteurs ont forgé leur poétique individuelle et leur identité comme groupe.

Mots-clés: revues poétiques, Indice, Juan Ramón Jiménez, poésie nouvelle, esthétique du groupe de 27.

Este artículo expone la importancia de Índice (1921-1922), revista de "poesía nueva» creada por Juan Ramón Jiménez, en la formación de los autores del 27. En sus 4 números publicaron Pedro Salinas, Jorge Guillén, Gerardo Diego, García Lorca... Varios años antes del centenario de Góngora en 1927, estos autores, inéditos en libro y muchos de ellos totalmente desconocidos, encontraron en sus páginas el cauce donde maduraron sus poéticas individuales y conformaron una identidad como grupo.

Palabras clave: revistas poéticas, Índice, Juan Ramón Jiménez, poesía nueva, estética del 27.

This article shows the influence of Indice (1921-1922), a «new poetry» journal created by Juan Ramón Jiménez, in the shaping of the authors of the ' 27 generation. Pedro Salinas, Jorge Guillén, Gerardo Diego, García Lorca, not yet published and totally unknown at that time, all were published in its 4 issues. A few years before Góngora's centenary in 1927, these authors found in its pages the medium where their individual poetics ripened and where they shaped a group identity.

Keywords: poetic journals, Índice, Juan Ramón Jiménez, new poetry, aesthetic of '27. 
G 1 siglo xx dio prioridad a nuevas formas de presentarse los poetas Cy las poéticas emergentes, que dejaron de hacerlo exclusiva o preponderantemente a través de libros individuales. La aparición de ciertos libros siguió señalando momentos bautismales o de confirmación de determinadas secuencias en el continuo estético de una época, por supuesto; baste pensar en el fragor público -aunque limitado al pequeño contingente de lectores de poesía- que supuso la edición de Prosas profanas (1896), de Rubén Darío, Campos de Castilla (1912), de Antonio Machado, o Diario de un poeta recién casado (1917), de Juan Ramón Jiménez. Junto a ellos, sin embargo, cobraron gran relevancia otros modos de manifestación artística, en especial cuando los autores ejercían de misioneros de una buena nueva poética, según fue propio de las vanguardias, o cuando lo hacían como miembros sedicentes de un grupo literario que buscaba afirmarse frente a los mayores.

Entre estos modos, dos son los más importantes, cada uno con sus particularidades: las revistas y las antologías. Así, los modernistas están conectados a diversas revistas de comienzos del Novecientos o a antologías como La corte de los poetas (1906), compilada por Emilio Carrere; los autores del ultraísmo surgen vinculados en su momento fundacional a revistas como Grecia o Ultra; y el grupo de poetas del 27 aparece ya con la escarapela canónica, tras diversos libros individuales y los festejos gongorinos de 1927, en Poesía española: antología 1915-1931 (1932), con Gerardo Diego como maestro de ceremonias. Es verdad que todo ello sería apenas nada si no hubiera libros para sostener ese estado de cosas que pergeñan las revistas y hacen que cuajen las antologías: por eso el modernismo y el 27 tienen el poso y el peso de que carece el ultraísmo, tan nutrido de proclamas teóricas (y aun así sin entidad doctrinal valiosa) como desguarnecido de libros que las justifiquen.

Los libros son la carta de naturaleza; las revistas y las antologías, la de presentación. Aquellos dejaron de tener la relevancia que tuvieron en la medida en que, desde fines del xix, aumentó sobremanera el número de los editados, y consiguientemente la dificultad para seguir su rastro y discernir el trigo de la paja; también por los procedimientos de implantación coral de ciertas instancias estéticas que trajo consigo la literatura posromántica. Estas -revistas y antologías- cumplen la tarea de filtrar, plantear y dejar constancia, convirtiendo el maremagno editorial de los volúmenes que de seguido salen de las prensas en un cartograma a escala y abarcable. Y aunque no sea este el lugar de desarrollarlo, dígase que la importancia de unas y de otras no se despliega en el mismo campo de batalla: las revistas -excluyamos los centones inespecíficos- suelen adelantar una situación que aún no ha cristalizado, y en este sentido proponen un dogma; las antologías proponen más a menudo un canon. Si la simplificación no resulta excesiva, aquellas inciden en la literatura; estas lo hacen en la historia de la literatura (al menos si tienen éxito: bien porque el futuro termina ratificando el pronóstico, bien porque la capacidad impositiva del pronosticador contribuye a conformar ese futuro a la medida de los pronósticos). 
Centrándonos en las revistas que constituyeron plataformas determinantes para la «nueva literatura» entre el posmodernismo y la floración poética que ocupó la década previa a la Guerra Civil, varias dependen orgánicamente de Juan Ramón Jiménez; entre ellas, Índice, Sí (Boletín Bello Español) del Andaluz Universal, Ley (Entregas de Capricho)... Resulta curioso que quien ha sido objeto de feroces caricaturas basadas en su solipsismo o su egolatría, y acusado de Saturno devorador ritual de sus hijos cuando estos comenzaban a levantar el vuelo, alentara y diera cuenta minuciosa del devenir de la poesía joven según esta se iba pronunciando; y ello sin paternalismos que anulan a quienes pretenden proteger, y sin tratar de difundir las poéticas propias por las personas interpuestas de sus discípulos.

Cada una de estas publicaciones registra notables rasgos de interés, pero sin duda es Índice (1921-1922) la que tiene mayor importancia. Y no me refiero a una mayor entidad artística, en cuanto continente de alta creación (que en algunos casos también lo es), sino a la importancia extrínseca o históricoliteraria que solo puede ponderarse contemplando aquello en que derivó y que contribuyó activamente a generar: nada menos que la red estética del 27, algunas de cuyas voces nucleares tuvieron en sus páginas el primer púlpito en que se hicieron oír y el crisol donde encontraron la familia en la que integrarse, según han valorado diversos autores (Cossío, 1970; Molina, 1990; Díez de Revenga, 1991; Guemárez, 1998; Henríquez, 2004-2005). Repárese en que se trata de voces que, por razón de edad, tenían escasísima presencia en la sociedad literaria española (y solo los mayores o los más precoces; los demás sencillamente no tenían ninguna).

Por la fecha en que se publicó, entre julio de 1921 y abril de 1922, Índice facilita datos para aquilatar el hiato entre los dos tramos cronológicos del 27, que suponen dos sistemas formativos diferenciados y dos modelos de constituyentes estéticos también distintos. En este sentido, más que un banco de pruebas del 27, Índice es un signo de interrogación sobre el propio sistema del 27. Nos servirá para verlo la acotación cronológica de la antología de 1932 de Gerardo Diego, y las tendencias acogidas en ella. Diego estableció su propuesta canónica sobre el lapso aproximado de quince años (1915-1931, precisaba el subtítulo), y no por la exigencia de caracterización orteguiana de las generaciones sino por la evidencia de que en esos años estaba cuajando el mapa de la poesía nueva. El final del periodo lo señalaban las poderosas corrientes surrealistas, miradas con gran recelo -a ello se deben las reticencias de Diego para incluir a Emilio Prados, y las de Prados para ser incluido- y pronto solapadas con las tributarias del compromiso sociopolítico. En dicha antología, los jóvenes aparecían arropados por los indiscutibles Unamuno, Manuel Machado, Antonio Machado y Juan Ramón Jiménez (quien rehusaría participar en la segunda salida, en 1934, mucho más nutrida de nombres «históricos»: tras los actos gongorinos de 1927, las iniciales fisuras se habían convertido en grietas aparatosas). Los nuevos poetas fueron afectados o no por el surrealismo dependiendo, sobre todo, de su fecha de nacimiento. Podemos usar como línea tajante el año 1898: los nacidos antes (Salinas, Guillén, 
Espina, Diego...) vivieron su proceso constitutivo con antelación a la epidemia surrealista; los que nacieron ese año (Lorca, Aleixandre, Alonso) o más tarde (Prados, Cernuda, Alberti, Altolaguirre...) lo hicieron cuando, por su juventud, aún tenían los poros estéticos bien abiertos para resultar contaminados. Por las citadas razones cronológicas, resulta lógico que Índice conectara con el espíritu del posmodernismo y la vanguardia ultraísta, sus gratuidades y sus propuestas deshumanizadoras, un paso antes de que derivaran en un esencialismo sin escayola formalista representado por el Guillén del primer Cántico (1928) o el Salinas de Seguro azar (1929). En otras palabras, Índice sirve de cauce para la corriente estética inicial de la "nueva literatura», que concuerda con los autores del primer segmento cronológico del 27, a la sazón inéditos en libro y varios absolutamente desconocidos. La denominación de "generación de Índice», alguna vez utilizada, se adecua a ese tramo creativo absorbido por el remolino general del 27 al que dio espaldarazo público la antología de Gerardo Diego; lo cual nos obliga a valorar como se merece la función tutorial de Juan Ramón Jiménez en la conformación de las poéticas de los años veinte.

La revista en cuestión constó de cuatro números, de los que en 1987 se publicó una edición facsímil. Entre los tres primeros y el cuarto hay ciertas diferencias de planteamiento. En aquellos, la revista se apostilla «Revista mensual» en la primera página del cuerpo textual, bajo el título. La idea era sacar diez números corrientes y dos extraordinarios al año, según se expresa en el primero, correspondiente a mayo; aunque ya desde el segundo, y con el afán de no evidenciar el retraso, se especifica que el primero corresponde a julio. No obstante la dilación que sufrieron las sucesivas entregas desde el comienzo, esos tres números mantuvieron el propósito de la mensualidad; pero el número 4 ya es de abril de 1922, lo que obliga a sustituir el primitivo subtítulo de «Revista mensual» por el de "Revista de definición y concordia». Hay noticia documentada de la existencia de un número 5, engendrado pero nonato, del que se dio el sumario y se corrigieron pruebas, y del que sabemos bastante (Henríquez, 2004-2005) a pesar de que no se haya podido seguir el rastro de estas. Debe suponerse que un conocimiento exhaustivo de ese número, en el que me demoraré luego, añadiría criterios más ajustados de estimación de la revista respecto a lo que podemos decir de ella a la luz de los cuatro números publicados.

Que Índice es una revista de nueva literatura parece excusado tener que argumentarlo; de otro modo no habría prestado su concurso principalísimo Juan Ramón Jiménez. Pero, siendo así, carece de toda vocación «de escuela» cercenadora en lo poético, y ni siquiera es una revista de grupo: quienes ahora se arraciman como una falange estética en los manuales de historia literaria bajo el marbete de "generación del 27", entonces apenas se habían tratado, o no lo habían hecho en absoluto. La voluntad integradora de la revista no era frecuente en las publicaciones de jóvenes. Claro que Índice no era una revista «de jóvenes» en un sentido estricto: estos eran los invitados, no los anfitriones. Respecto a esa condición de revista integradora y no de grupo ni de cerrada 
corriente estética, da testimonio la nota de la contracubierta posterior en los tres primeros números:

índice no es revista de "grupo». Sus redactores son escritores y artistas de las más distintas tendencias, españoles e hispano-americanos, unidos solo por el interés común de la exaltación del espíritu y por el gusto de las cosas bellas.

En sus páginas, cabrá todo lo que signifique "vida», desde lo más acrisolado hasta lo más nuevo, desde lo más llano hasta lo más insigne, desde lo más oculto hasta lo más abierto; y su aspiración es llegar a definir y deslindar, del modo más completo y perfecto posible -con un criterio amplísimo y estrechísimo a un tiempo-, la calidad más noble del genio espańol e hispano-americano.

Hoy, índice no cuenta sino con el entusiasmo de sus colaboradores, primeros suscritores y redactores. Estos últimos están dispuestos a todos los esfuerzos y sacrificios necesarios, hasta conseguir que España tenga, con permanencia, una revista -no pretendemos decir la única- libre, generosa y pura.

Para su mejora constante, en lo íntimo y en lo material, ínDICE admite consejos y donativos.

Leída por alguien familiarizado con las manifestaciones beligerantes de las revistas de vanguardia, la nota reproducida invita a pensar en falta de personalidad artística. En efecto, así se considerará si entendemos la personalidad como una delimitación previa en el mapa de líneas poéticas, y no como una restricción fundamentalmente cualitativa respecto a los productos en ella incluidos (que no renuncia, por supuesto, a una idea de novedad incompatible con ciertos estigmas del realismo del xIx). El «criterio amplísimo y estrechísimo a un tiempo" no es una paradoja inane, sino expresión de lo señalado: apertura en lo estético, estrechez en las exigencias de calidad. Cuando el mexicano Alfonso Reyes, que colaboró desde el primer momento en Índice mano a mano con Juan Ramón Jiménez, afirmaba años después que la revista no ofreció programa alguno, no quiso con ello decir que su sincretismo derivase de la falta de principios estéticos, sino que «demostraba el movimiento andando» (1990: 181); lo que cabe entenderse como que su discutida personalidad no se estipulaba en preceptos apriorísticos de carácter dogmático, sino que se manifestaba en los postceptos o resultados (por usar los deslindes de Unamuno en su poética para la antología de Diego de 1932). El criterio de calidad había sustituido a cualquier forma de sectarismo: "Quiso ser un centro para los escritores jóvenes de Espańa que se distinguieran, cualquiera que fuese su tendencia, por la seriedad y pureza de sus intenciones literarias. En rigor, lo logró en los pocos números publicados» (Reyes, 1996: 155). Lo que no impide que determinadas líneas creativas fueran repudiadas en cuanto seña de una literatura periclitada (presimbolista, ideologizante, declamatoria...) para la que no había lugar en Índice. Existen expresiones documentales que ejemplifican lo dicho y patentizan la exigencia de la selección en la confección de la revista. En carta de 17 de mayo de 1922, escrita al «Sr. Administrador» desde Rosario de Santa Fe (Argentina) por el poeta regionalista murciano Vicente Medina, 
en que le propone difundir la publicación comercialmente en aquel país según criterios distintos a los de la suscripción establecida con carácter general, Juan Ramón, a pesar de las estrecheces económicas y de su voluntad de propagarla internacionalmente, manuscribe al pie de la carta para encauzar la respuesta del secretario-administrador: «No, porque vendrá el compromiso sabido» (Díez de Revenga, 1991: 134-135). Para el Andaluz Universal, los requerimientos de la nueva literatura estaban muy lejos de lo que podía aportar un Vicente Medina, paradigma de la «vieja literatura» de signo costumbrista.

A lo largo de sus cuatro números no hay referencia al director de la revista; aunque a todos los efectos, salvo al de la constancia documental, el director y fundador es Juan Ramón Jiménez. Tratándose del moguereño, ello no solo implicaba exigencia en la aceptación de las colaboraciones, sino rigor extremo en los rasgos formales de la publicación: formato, tipos, tintas, disposición de los textos, etcétera. Mucho más que un contenedor de literatura, para Juan Ramón Jiménez una revista era una obra artística en sí misma, cuyos rasgos plásticos habían de estar en consonancia con los contenidos. Tampoco hay referencia al secretario en el número 1; pero sí en el 2, donde, en la contracubierta posterior, y encima del texto reproducido atrás, se cita a Ricardo Díez-Canedo como receptor, en su condición de tal, de toda la correspondencia, libros y revistas. En el número 3 aparece, en el mismo lugar, el nombre de Juan Guerrero Ruiz como secretario de Índice, que se mantiene, aunque en otra ubicación, en el número 4.

Desde el comienzo se establece la diferencia entre redactores y colaboradores, y así se refleja en los diversos sumarios junto al nombre y al título de las respectivas aportaciones; aunque no hay una nota precisa con la nómina de redactores, y la disposición tipográfica de los sumarios no siempre ayuda a discernir unos de otros. En la página del sumario, que en todos los números ocupa la contracubierta anterior, figuran abajo unas notas, la última de las cuales especifica que «ÍNDICE elige sus colaboradores a gusto de sus redactores». Entre los redactores, que sostenían económicamente la revista y se encargaban de confeccionarla, hay que contar, junto a Juan Ramón Jiménez, a Alfonso Reyes principalmente; también a José Bergamín y Enrique Díez-Canedo, que tras el primer número desatiende esa obligación pecuniaria ${ }^{1}$, aunque siguiera colaborando hasta el final con una implicación menor. En el número 4 (algo que puede aplicarse al fallido número 5) fue Juan Ramón quien cargó sobre sus hombros el peso de la redacción y de la composición, sin cirineo que le ayudara sustancialmente en la tarea, salvando a su fidelísimo Juan Guerrero Ruiz. Ese número presentaba ciertas innovaciones que respondían a la aludida soledad de Juan Ramón y, también, a la voluntad de algunas mejoras. A ello se referiría en sus confidencias a Juan Guerrero, quien el 7 de marzo de 1922

1. En carta al secretario de Índice Juan Guerrero Ruiz, de 30-XII-1921 -cuando se habían publicado tres números de la revista-, Enrique Díez-Canedo justifica el impago de dos cuotas apelando a su mala situación económica, y apostilla: «de no ser así no hubiera esperado a que V. me lo recordara» (Díez de Revenga, 1991: 127). 
alude a las dificultades de que le había hecho sabedor el poeta, y a la decisión juanramoniana de proseguir con el empeño, tras ciertas vacilaciones: «Después de unos días de crisis ha decidido continuar la publicación de la revista Índice, variándola. Quedan para 1921 los tres números ya publicados, con cubierta amarilla, y ahora saldrá sin carácter mensual, únicamente numerada» (Guerrero, 1998: 51).

Las entregas de la revista tienen 16 páginas numeradas la primera, y 24 las tres restantes. Se excluyen de esta cuantificación las páginas del comienzo y del final, así como un suplemento consistente en una hoja suelta sin numerar. La idea de continuo queda subrayada por el sistema de numeración. Las cuatro entregas utilizan un procedimiento de numeración doble, arábiga y romana; pero aquí difiere la concatenación entre los tres primeros números y el cuarto. Así, aunque todos comienzan por el I romano (hasta el XVI el primero, y hasta el XXIV los otros tres), los arábigos son consecutivos en los tres primeros (1-16 el primer número; 17-40 el segundo; 41-64 el tercero), en tanto que el cuarto se inicia de nuevo con el 1, lo que marca su carácter relativamente exento respecto a los restantes. En la última página numerada del cuerpo interior de la revista se especifica el establecimiento de impresión: en la Imprenta Maroto los números 1 y 2 , en Talleres Poligráficos los números 3 y 4.

En lo concerniente a la estructura y distribución, se mantiene una homogeneidad sustancial en todos los números, con ciertas salvedades en el cuarto. Las entregas 1-3 presentan, antes de las páginas numeradas que constituyen el núcleo con los textos de la revista, cuatro páginas: 1, cubierta anterior, en el característico amarillo de Juan Ramón (ÍNDICE / [número] / Madrid / 1921); 2, contracubierta anterior («Sumario»); 3, publicidad (librería y encuadernación); 4, «Bibliografía titular selecta» (información que continúa en la página siguiente del pliego, la primera de las del final). En la parte del final están las cuatro páginas correspondientes: 1, información de libros y revistas (continuación de la «Bibliografía titular selecta» del comienzo); 2, publicidad editorial; 3 , contracubierta posterior con nota informativa (con el texto reproducido atrás y, a partir del número 2 , con el sumario del número anterior); 4, cubierta posterior. Las dos hojas del pliego interior a las cubiertas, donde constan los contenidos bibliográficos, vienen en tono rosa con tipos violetas, y numeran sus cuatro páginas independientemente del cuerpo de la revista.

El número 4 tiene seis páginas al comienzo: 1, cubierta anterior (ahora blanca y a dos tintas, y con una relación de los colaboradores en el centro de la página; el año es ya 1922); 2, contracubierta anterior («Sumario»); 3, nota informativa a modo de portadilla (que corresponde a la nota informativa que en los otros números aparece al final, encabezada con el título y el nuevo subtítulo: «Revista de definición y concordia»), con datos relativos al precio y el texto que se ha reproducido atrás; 4, sumario de los números 1-3; 5, «Explicación a nuestros amigos» (donde se da cuenta de las dificultades y retrasos y de la reducción de entregas anuales, que estarán entre ocho y doce, «aunque anteponiendo siempre la calidad de su sumario a la exactitud de su fecha»); 6, blanca. Respecto al final, 
se eliminan las páginas de información de libros y revistas y de publicidad, y pasa la nota informativa a página 3 de las del inicio, desgajándose de ella el sumario -que no se ciñe solo al número anterior, como en los otros casos, sino a los tres primeros-, que ocupa la página 4 del comienzo.

El texto se reparte en dos columnas, alternando prosas y versos, ensayo y creación, y sin solución de continuidad entre lo uno y lo otro incluso dentro de la misma página. Esta ausencia de blancos produce una cierta impresión de falta de aire, contrarrestada por la belleza tipográfica y la limpieza en la distribución. Aun cuando se trata de una justificación retrospectiva tanto como de un propósito para un futuro que ya no tendría lugar, la «Explicación a nuestros amigos» del número 4, y a modo de encarecimientos y disculpas de retrasos y modificaciones, especifica que la revista tiene vocación de inactualidad, no se presta a "concesiones más o menos necesarias y rellenos de piedra», y busca en todo caso, al margen siempre de intereses de grupo o parcelas de influencias, «la máxima perfección posible, ética y estética»; también, hubiera podido añadir, de continente y de contenido.

Respecto a este último, y según se evidencia en los sumarios, en Índice hay algunas secciones fijas que permiten percibir la línea de homogeneidad en la revista y están sostenidas por los redactores; y los textos, esporádicos o regulares, de los colaboradores. Lógicamente, las secciones fijas manifiestan mejor que las colaboraciones el espíritu fundacional de Juan Ramón Jiménez y sus cooperadores más próximos; pero las colaboraciones, al albur del talento individual, potencian la visión de la literatura emergente.

Entre esas secciones fijas destaca la llamada "Antología española», mucho título para tan exiguas muestras a tenor de lo publicado en la corta existencia de Índice, pero de gran interés representativo puesto que orienta sobre las pautas procedentes de la tradición que la nueva literatura consideraba vigentes o aprovechables. Esta propensión a incluir determinadas tradiciones en el cañamazo de las estéticas contemporáneas es algo irrenunciable en las poéticas del 27. Frente a las expresiones más decantadamente vanguardistas, cuya iconoclasia parecía formar preceptivamente parte de su sistema, los jóvenes de la estela juanramoniana supieron -porque previamente quisieron- armonizar tradición y ruptura; o, si se prefiere, cultivaron la novedad a partir de esquejes provenientes del huerto de la tradición. Y si, como antes se ha señalado en contra de apresurados impresionismos, Juan Ramón dista de ejercer de Saturno con sus discípulos, estos atendieron a una parte de la tradición antecedente con respeto y hasta con devoción (otra cosa es que, muchos de ellos sí, terminaran devorando al padre; pero el fundamento de tal actitud futura contra Juan Ramón es psíquico y no estético, y no resulta de aplicación general en la postura del 27 ante la tradición, en este caso inmediata).

Algunos años atrás, los autores de fin de siglo habían reivindicado a los primitivos medievales o al Greco para despegarse del viejo arte personalizado en «las solemnes calvas de la Real Academia» (Carrere, 1906: 7), paradigma de la esclerosis formalista y del realismo ramplón; ahora correspondía a los seguidores juanramonianos poner el acento en interesantes zonas de la historia 
literaria: Romancero (número 1), Cancioneros (2), Góngora (3) y Sem Tob (4). Para el número 5 estaba previsto Gil Vicente. Y no es este un asunto baladí, por lo que supone de relativa novedad y de orientación a quienes se irían incorporando a la nueva literatura. Allí había popularismo por todos los lados, especialmente por el lado culto (la selección de Góngora responde también a ello), que resulta indicativo de las afinidades electivas de los jóvenes. Antes de que surgieran los primeros títulos relevantes del 27 y se constituyeran sus poéticas individuales - «romanceros» de Diego o de Lorca, «cancioneros» de Alberti o de Prados, literatura gnómica de Bergamín...-, esa microantología dejaba ver las estancias de la tradición que los jóvenes encontraban susceptibles de apropiación. Hubiera sido difícil precisar más con menos propuestas. Ello no obstante, no conviene exprimir la observación más de lo que aconseja el sentido común: de la minúscula antología no cabe deducir jerarquías ni muy definidas ni mucho menos definitivas, aunque valga como síntoma. Ir más allá solo estaría justificado si la susodicha antología tuviera cuerpo suficiente para que pudiéramos percibir, junto a lo seleccionado, lo desestimado; y no es el caso.

Otra sección de Índice es «Traducciones», que podría haber contribuido al discernimiento de los autores tenidos por modelo entre los coetáneos de otras lenguas, como había hecho la "Antología española» con los clásicos en lengua propia. Y así habría sido probablemente si la sección hubiera dependido de Juan Ramón Jiménez y del cuerpo de redactores; pero el responsable único es E. Díez-Canedo, a quien se deben todas las versiones: de Jens Peter Jacobsen en el número 1, Vicenzo Cardarelli en el 2, y Hugo von Hofmannsthal en el 4 (en el número 3 no hay sección de traducciones). Para el número 5 se anunciaba a Camillo Sbarbaro. Dicho lo anterior, y sin contar con que las limitaciones que veíamos a propósito de la "Antología española» se dan también aquí, la información que nos proporciona esta sección, a los efectos que nos interesan, es muy poco relevante: todo lo más ilustra sobre el conocimiento o las preferencias de Enrique Díez-Canedo acerca de la literatura europea contemporánea.

La sección de "Cartas», por su parte, queda atenida a pequeños episodios bibliográficos o anecdóticos, más allá de la del severo Julio Cejador en el número 2. En él se refiere con acrimonia de dómine a la «superchería» del primer número, que publicó en el suplemento del mismo -una hoja suelta y sin numerar, como en los demás casos- un breve epistolario cruzado entre Góngora y el Greco que los redactores presentaban como verdadero, y que remueve la cronología gongorina al punto de anticipar la génesis de las Soledades cuando menos veinticinco años; lo cual es de tanto bulto que podría haber bastado para evidenciar la broma de los redactores, que parece no asumir Cejador, temeroso del perjuicio que pudiera hacerse a los semieruditos: "Como las supercherías, cuando no se publican en broma, sino muy en serio, como en el presente caso, pueden hacer mucho daño en la república de las letras, todos los ciudadanos de ella tenemos cierta obligación de combatirlas y desenmascararlas». La contestación de los redactores no es menos jocoseria que su primera intervención -la de las cartas fingidas- y dice mucho del tono 
general de la revista. Por lo demás, la sección es poco nutrida (y varias cartas son de miembros de la redacción).

Otra de las secciones es "Bibliografía titular selecta», cuyo interés radica en las listas de libros (de autores españoles o no) y revistas de varios países efectuadas por los redactores, y que sirve tanto como la relación de títulos reseñados en los actuales suplementos literarios de los grandes periódicos. Una bibliografía selecta representa, en lo contemporáneo y universal, también una suerte de propuesta canónica. Por lo que a libros respecta, junto a autores en castellano, hay otros de lengua francesa fundamentalmente en los casos en que se dan títulos originales (aunque hay ejemplos de otras lenguas: catalán y portugués en el número 1; italiano, inglés, alemán). Esta sección debió de ser una de las que se consideraron prescindibles porque, en las explicaciones del número 4 «a nuestros amigos», se alude a la corrección -entiéndase eliminación- «de elementos secundarios que eran parte de su rémora»; y este fue uno de los «elementos» que desapareció en ese número (aunque cabe maliciarse que, al fondo, esté la comentada soledad de Juan Ramón Jiménez, especialmente gravosa en secciones corales como esta, precisadas de cooperadores que estuviesen al tanto de publicaciones recientes, y que a esas alturas habían dejado de brindar su concurso).

Característico de esta revista es un suplemento en hoja exenta sin paginar, del que estaba encargado el cuerpo de redactores -en realidad, Enrique DíezCanedo y Alfonso Reyes, si hemos de hacer caso a este último- ${ }^{2}$, y que consistió, respectivamente, en lo siguiente: número 1, «La rosa de papel (Góngora y el Greco)», a que ya nos hemos referido atrás, sobre un epistolario inédito entre Góngora y el Greco, que se reproduce y comenta y que la revista presentó como verdadero; número 2, «El lorito real (música y doctores)», que comienza razonando sobre la música en relación con otras artes y concluye haciéndolo sobre las artes en general, a menudo enfrentadas a la "superstición de la ciencia»; número 3, «Debate entre el vino y la cerveza», donde los redactores remedan con regodeo erudito los debates medievales en el tono jocoso que solo se adivinaba en las dos primeras entregas; el número 4, en esta ocasión sin texto, incluye un dibujo del polaco Wladyslaw Jahl (una silueta en blanco y negro titulada en el índice "Desnudo»). Excluido este último, los otros presentan como encabezamiento del escrito un dibujo en color firmado por «M.», que probablemente respondía al impresor [Gabriel García] Maroto, quien en el primer número figura como redactor de la revista y autor de uno de los textos.

La falta de un surtido más amplio de números para poder establecer algunos principios generales desaconseja también en el caso del suplemento interpretaciones excesivas. El número 4 quiebra el aire festivo o diletante de los anteriores, en que una erudición trufada de desparpajo replica lúdicamente

2. «En los suplementos, Enrique Díez-Canedo y yo inventábamos cartas cambiadas entre el Greco y don Luis de Góngora, un debate medieval entre Don Vino y Dońa Cerveza, nos reíamos de los que discutían en serio nuestros documentos imaginarios, hacíamos un palmo de narices al "espíritu de la pesadez"» (Reyes, 1990: 181). 
a la erudición y la creación serias. En el proyectado número 5 estaba previsto un facsímil del manuscrito de Rubén Darío «En el país de las alegorías», lo que incita a suponer nuevos derroteros para la sección. El procedimiento de presentar este apartado en cuerpo anexo indica la complementariedad -congruencia y distancia a un tiempo- con el cuerpo central de la revista. El recurso fue seguido por otras publicaciones que, en alguna medida, tienen aquí un precedente; así, la desenfadada Lola, «amiga y suplemento de Carmen», de Gerardo Diego (diciembre 1927-junio 1928). En Lola la apoteosis gongorina y los festejos aledaños dieron pie a hilarantes jinojepas, cuya definición de género queda prendida de su propia fonética; a los juegos de Don Acróstico y Doña Charada; o a la selección efectuada en la Tontología, antología de versos malos de poetas buenos. Y aunque Índice apenas supuso una breve incitación, resulta notoria su autoridad rectora y la irradiación de su influencia en quienes cobrarían protagonismo en $1927^{3}$.

Por lo que se ha visto, sus secciones regulares permiten entender la revista como una cierta proclama artística, con las cautelas ya expresadas: lo son la antología, las traducciones, las selecciones bibliográficas... Hay otras secciones de hecho, aunque no figuren como tales al quedar referidas al tipo de colaboración de algún autor. Es el caso de las aportaciones de Juan Ramón Jiménez, todas las cuales aparecen bajo el mismo rótulo, "Disciplina y oasis», que subtitula "Anticipaciones a mi obra», donde iba incluyendo versos y prosas de su obra en marcha. No difiere mucho Enrique Díez-Canedo, cuyas intervenciones, al margen de las traducciones, tienen el mismo título, "Tópicos», sobre temas literarios y con un tono entre ensayístico y creativo (aunque en el número 3 cesó en esta participación, limitándose desde entonces a las traducciones). La heterogeneidad temática de otros redactores impide entender sus aportaciones como auténticas secciones fijas: así Alfonso Reyes o Adolfo Salazar. Pero si hay algo que, por encima de otras cosas, permite determinar una propuesta canónica, según se apuntó atrás, es el nombre de los colaboradores. En tanto que revista de nueva literatura, tan importantes son las firmas que podían rescatarse de los consagrados, y que cabía interpretar como modelos para los jóvenes, como las de quienes velaban sus primeras armas en una plaza regida por Juan Ramón Jiménez, principal referente, con Antonio Machado, de la

3. Esa influencia, tan perceptible en las citadas Carmen / Lola, se manifiesta incluso contra el propio Juan Ramón Jiménez, que se desentendió de la revista de Diego en una acerba carta firmada en Lola como «K, $Q, X$.» y dirigida a Rafael Alberti en contra de Gerardo Diego; la entidad de Góngora, afirmaba Juan Ramón, pedía «director más apretado y severo, sin claudicaciones ni ideas fijas provincianas» (número 2, enero 1928). Las reacciones desabridas de algunos escritores ante textos de Lola reproducen el tono ya comentado de Cejador a propósito de la broma epistolar sobre Góngora y el Greco. Así, la carta de Azorín a Gerardo Diego en el número doble 3-4 de Lola (marzo 1928), reputándose desde siempre elogiador, admirador y lector de Góngora, y no, como se había afirmado en el número 2, enemigo de Góngora y corresponsable de que la RAE no le rindiese homenaje alguno con motivo del tercer centenario de su muerte. Como Cejador en Índice, Azorín quiere dejar la verdad explícita, a pesar de "todos los divertimientos que usted quiera; todas las gambetas, morisquetas y cuchufletas que a usted le plazcan». 
poesía española (el caso de Unamuno no es homologable, pues el respeto que muchos jóvenes pudieran sentir por él no es siempre de índole estética).

Acerca de los colaboradores, es importante comprender la función de Indice como tribuna puesta al servicio de quienes, andando pocos años, habrían de nutrir el espacio de la renovación poética; pues aunque programáticamente la revista careciera de ataduras de grupo, lo cierto es que en ella escribían solo «los jóvenes o los juveniles, y algunos hicieron allí sus primeras armas» (Reyes, 1990: 180); verdad es que arropados por quienes, ya no estrictamente jóvenes, daban con su autoridad el espaldarazo a una concepción innovadora de la literatura.

El número de colaboradores ronda la treintena. Ciertamente, la totalidad de nombres que vienen a colación es mayor, pero varios se anunciaban solo para el nonato número 5 (Alonso Quesada, Carlos Pellicer, E. González Martínez, José Ballester ${ }^{4}$, Luis G. Santa Marina), y otros son autores traducidos, o clásicos para las páginas antológicas. A pesar de que el núcleo de los redactores tenidos por tales es pequeño, son bastantes los colaboradores regulares que, un número tras otro, cumplen una tarea de decantación estética semejante a la de aquellos, aunque sin sus obligaciones en la confección material de la publicación. Así, dejadas estas distinciones a un lado, junto a Juan Ramón Jiménez, Alfonso Reyes, Enrique Díez-Canedo -reducido en el número 4 y el proyectado 5 a su quehacer de traductor- y Adolfo Salazar, participantes en todos los números publicados y con presencia prevista en el 5, deben consignarse los nombres de Pedro Salinas (hay textos suyos en los cuatro números publicados), José Bergamín y García Lorca (están presentes en todos los números a partir del 2, incluido el proyectado 5), Moreno Villa (en los tres primeros), Corpus Barga (en todos los publicados, salvo el 3), Jorge Guillén (en todos los publicados, salvo el 1). Otros autores jóvenes están en un solo número: Gerardo Diego y Dámaso Alonso, en el 3; Juan Chabás y Antonio Marichalar, en el 4; Antonio Espina -al igual que Gómez de la Serna- en el 2 (aunque estaban programados para el 5)... Alguna curiosidad más: los escritores españoles de generaciones anteriores a la del propio Juan Ramón, con la función de contribuir al reconocimiento de la revista y apoyar con su prestigio a los jóvenes, son Azorín (número 1), Manuel Machado (3) y Antonio Machado (4); Ortega y Gasset, coetáneo de Juan Ramón, abre el número 1.

La revista había nacido con vocación española e hispanoamericana, y el protagonismo desde el primer momento de Alfonso Reyes confirma la vocación transatlántica. No obstante, la participación de autores no españoles fue muy limitada: además de Reyes, los mexicanos José Juan Tablada, Genaro Estrada (ambos en el número 4), Enrique González Martínez y Carlos Pellicer (los dos

4. El escritor murciano José Ballester cobra gran importancia en la historia documental de Índice, como allegado y amigo de Juan Guerrero, director que fue del Suplemento literario del diario murciano La Verdad -que luego se transformarían en Verso y Prosa por iniciativa de Jorge Guillén y del propio Guerrero- desde 1923, año en que Ballester ingresa como redactor. Ballester fue el receptor de la documentación acopiada por Guerrero relativa a Índice (en su mayor parte, cartas en torno a suscripciones, pagos y asuntos semejantes), y de su archivo pasó finalmente al de la murciana Academia Alfonso X el Sabio (Díez de Revenga, 1991: 111-112). 
últimos estaban previstos para el 5), el dominicano Pedro Henríquez Ureńa (1 y previsto para el 5) y el venezolano J. Gil Fortoul (3).

A los efectos que aquí interesan, es más indicativa la nómina de los colaboradores que la entidad estética de sus trabajos. No interesa tanto evaluar los textos en su condición de productos poéticos en cuanto tales, como percibir el intento de Juan Ramón y sus cooperadores más cercanos de dar cancha a autores jovencísimos que, ni siquiera estrechamente homogéneos o concordantes entre sí, presentaban credenciales artísticas que había que seleccionar, canalizar y exponer. El criterio de elección o de aceptación de los textos no obedecía a pautas unitarias. En algunos casos, se trataba de mostrar obra inédita en el proceso de organización y composición del libro en el que se integraba (o al margen de todo proceso consciente de composición de un volumen); otras veces se incluía obra ya publicada, como altavoz a determinado libro del que procedía. Pero quizá lo más notable sea el modo en que la revista sirvió como banco de pruebas que permite asistir al desarrollo de un poeta en agraz. Frente a lo que sucede con las secciones fijas, en que la escasez de materiales obliga a relativizar las conclusiones que puedan obtenerse, aquí sí hay materiales suficientes, que procedían de libros o que fueron a parar a libros, que constituyen antetextos o que son ya textos finales, que deben entenderse como parte del todo al que pertenecen o que son, en sí mismos, materiales exentos y totales... Y aunque no cabe analizar ahora tan variada casuística, citaré algunas colaboraciones de poetas centrales del 27 que responden a la pluralidad referida y que son susceptibles de dicho análisis.

Dámaso Alonso publicó en el número 3 (1921) dos composiciones de su libro Poemas puros. Poemillas de la ciudad, que acababa de aparecer en la primavera de ese año. Sobre la pésima suerte comercial del volumen el propio Dámaso Alonso dejaría un testimonio gracioso ${ }^{5}$; de modo que la inserción en la revista de los poemas ya editados («Los contadores de estrellas» $\mathrm{y}$ «Gota pequeña, mi dolor») pudo salvar de la absoluta irrelevancia pública al librito con que se había estrenado su autor, y que hasta 1944 fue el único suyo de creación poética. En ese mismo número dio a conocer Gerardo Diego tres poemas: «Estética», "Verbos» y "Movimiento perpetuo»; en este caso, sin embargo, del libro aún inédito Imagen, que se anunciaba en la revista como de próxima publicación (lo imprimió al año siguiente Gráfica de Ambos Mundos, de Madrid). De cualquier modo, tanto Dámaso Alonso como Gerardo Diego entregaban a la revista composiciones pertenecientes a libros que, inéditos o no, respondían al presente de su curso formativo como poetas.

5. El libro (Madrid, Galatea, 1921) salió junto a Espejos, de Juan Chabás, por intermediación de Manuel Machado, a quien se dirigieron ambos autores. La editorial con cuyo dueńo, amigo suyo, lo puso en contacto, quebró apenas publicado el libro, que quedó abandonado a su mala ventura. Escribe Alonso en sus Poemas escogidos, de 1969: "Yo solo tuve un comprador; un homónimo absoluto mío, militar -muy simpático-, que, un par de años mayor que yo, estaba de guarnición en Ceuta y compró de una vez cincuenta ejemplares. Y tuvo grandes éxitos entre las seńoritas de la plaza a las que se los regaló con madrigalescas dedicatorias firmadas por él» (1993: 68). 
Otro es el caso de Jorge Guillén, que publica en el número 2 un romance («Poniente de bronce», estructurado en dos series con distinta rima) y dos prosas en los números 3 («Ventoleras») y 4 ("Circunloquios»), mucho antes de que saliera en 1928 su Cántico, buena parte del cual había ido adelantando en revistas como Alfar, Revista de Occidente, La Gaceta Literaria, La Pluma, Verso y Prosa, etc. En la medida en que Guillén asoma en volumen como poeta ya formado y su libro tiene una plena constitución orgánica, el estudio de sus contribuciones a Índice alumbra los eslabones sueltos anteriores al primer Cántico.

Pese a su juventud, Federico García Lorca es una firma fija en la revista a partir del número 2; de los nombres de su entorno, él es quien cobra mayor relevancia en tanto que poeta, pues las colaboraciones de otros autores del grupo, como Salinas o Guillén, asimismo asiduos, son en verso o en prosa, y esta creativa o ensayística. Las composiciones lorquianas corresponden al mundo poético de las Suites, que vertebran un tramo de su trayectoria: a él pertenecen los polípticos “"Suite” de los espejos» (número 3) y «Noche» (número 4), y muy próximo a él es el poema también en partes «El jardín de las morenas» (número 2).

Habitualmente, cuando los poemas de estos autores figuran en un libro de su corpus bibliográfico editado casi simultáneamente a su inclusión en la revista, no suelen decirnos nada del proceso de creación del texto ni del de maduración del poeta (así, en los casos citados de Dámaso Alonso y de Gerardo Diego); algo especialmente evidente cuando, como en el ejemplo de Dámaso Alonso, los poemas de la revista son mera reproducción de los ya dados a conocer en el libro. Otras veces, sin embargo, el poema queda sin recoger en volumen, expresión de que el autor llegaría a verlo como ejercicio de aprendizaje del que, en el momento de publicar su obra, ya se siente distante; ese es el caso del romance aludido de Jorge Guillén, cuyo simbolismo (bronce negro, bronce verde) está sujeto a una enunciación machacona que difiere mucho del universo del primer Cántico.

En ocasiones, el poema de la revista termina incluyéndose en un libro que se edita algún tiempo después; en tal circunstancia, la distancia cronológica nos permite asistir al proceso de las modulaciones y correcciones del texto por parte del autor hasta su formalización definitiva en el volumen. Es el caso de Pedro Salinas, pieza importante en todos los números de la revista, en la que publicó versos (números 1 y 4 ) y prosas (números 2 y 3). Si atendemos, por ejemplo, a una de sus composiciones del número 4 («Poesías», I), vemos la evolución evidente desde la versión de la revista a la del volumen, Presagios, aparecido en la «Biblioteca de Definición y Concordia» en que se prorrogó la aventura de Índice 6 . Fue Juan Ramón, por cierto, el encargado de la corrección y ordenación de los poemas que le había pasado Salinas, como este mismo cuenta en carta de

6. Madrid, Índice, 1924. Aunque el libro lleva fecha de 1923, apareció en realidad el 30 de enero de 1924, como número 7 de la Biblioteca, y con un prólogo de Juan Ramón Jiménez («Visita de Pedro Salinas»). 
25 de noviembre de 1923 a Jorge Guillén ${ }^{7}$. Rezan así las versiones de la revista, primero, y la de Presagios según figura en su poesía completa (Salinas, 2007: 120), a continuación (las cursivas son mías):

\author{
Hoy te han quitado, naranjo, \\ todas las naranjas de oro. \\ Las meten en unas cajas, \\ $y$ las llevan a Inglaterra. \\ [...]
}

Hoy te han quitado, naranjo, todas las naranjas de oro.

Las meten en unas cajas $y$ las llevan por los mares a tierras sin naranjal.

$[\ldots]$

El resto del poema no sufre modificaciones; pero basta fijarse en los dos versos señalados en la versión de Índice (tres en la del poema en volumen) para comprobar cómo la referencia casi costumbrista de la revista se deslíe parcialmente y pierde concreción para mantener el pulso lírico en la versión ulterior. Y, aunque no procede aquí, otro tanto cabría hacer con los poemas II y III incluidos en el mismo número de la revista y pertenecientes también a Presagios; en especial con el último, donde muy pocos cambios (¿puede que algunos debidos a sugerencias del propio Juan Ramón?: la carta citada de Salinas a Guillén permite suponerlo) resuelven problemas de eufonía, de tono, de estética en suma, revelando el sentido de la evolución del poeta.

He indicado atrás las dificultades de Juan Ramón para mantener la revista después del número 3, dada la carestía de su impresión y las deserciones de algunos, que se veían requeridos a pagar cantidades importantes para la época. El número 4 todavía pudo salir, aunque trastabillando y con algunos meses de retraso, y sabemos que el 5 estuvo corregido en pruebas -tarea que correspondió a Juan Guerrero, como le recuerda alguna vez Juan Ramón-. El 5 de abril de 1922, El Sol anunciaba la salida para ese mismo mes de los números 4 y 5, de los que daba el sumario (Henríquez, 2004-2005: 298-299). En abril, en efecto, vio la luz el número 4; pero no así el 5, en el que colaboraban, según la información de El Sol, E. González Martínez, Ramón Gómez de la Serna, Luis G. Santa Marina, Alonso Quesada, José Ballester, Alfonso Reyes,

7. «Total y dicho más sencillamente: que el mismo día que salí de Madrid, 25 de octubre, llevé a Juan Ramón mis versos, relativamente en limpio, y sin corregir ni ordenar; que él se encargó benévolamente de poner aquellas poesías en cierto posible orden, y si resultaban bien hacer un libro, y aquella misma noche me vine a Sevilla, en donde espero aterrorizado la llegada de las pruebas. Como usted ve es la historia del “¡Ahí queda eso!”. Y la única curiosidad que tengo es la de ver cómo se las ha compuesto J. R. para reducir a un libro las poesías de tan distintas épocas y acentos que yo le dejé» (en Salinas \& Guillén, 1992: 42). Lo cual se hace constar para que pueda percibirse mejor el mecenazgo de Juan Ramón y su protagonismo en la constitución estética de los poetas jóvenes a quienes dio acogida en Índice. 
Pedro Henríquez Ureña, Antonio Espina, José Bergamín, Federico García Lorca, Adolfo Salazar, Juan Ramón Jiménez, Carlos Pellicer..., sin contar las secciones "Antología española», "Traducciones», "Cartas» y "Suplemento», de cuyos contenidos ya se ha hablado. Y todavía hay más. En una carta de Zenobia Camprubí a Juan Guerrero, de 28 de agosto de 1922, pasa revista a las actividades de su marido, y apostilla: «el número 5 de Índice ha de quedar publicado y preparado el 6» (Camprubí, 2006: 11); y líneas abajo le comenta que el número 5 aún no había salido por un retraso de Reyes, encargado de ultimar con la imprenta el asunto, además de otros problemas, entre ellos el pico de una deuda del número precedente a la imprenta, que constantemente le reclamaba [José] Maíz. En otros lugares y momentos insiste en los problemas económicos debidos en primer término a que los propios redactores no pagaban las cuotas. Todavía en carta a Guerrero de 3 de octubre de ese mismo año, anuncia Zenobia la inminencia de publicación de un nuevo número que nunca habría de salir ${ }^{8}$.

Pero la aventura de Índice no quedó encallada ahí, según se ha anticipado ya. En 1923 decide Juan Ramón aplicar el espíritu de la revista a una colección de libros («Biblioteca de Definición y Concordia», marbete tomado del subtítulo de la revista en el número 4), a la que se refiere con estas palabras Alfonso Reyes, quien abrió la colección con la segunda edición de su Visión de Anáhuac y publicó en ella una edición del Polifemo gongorino: «Ahora su director ha preferido transformarla en una colección de libros breves (alrededor de seis pliegos en $8 .^{\circ}$ ), y presentados con esa excelencia que hace del poeta Jiménez un maestro del libro español en el sentido editorial y artístico» (1996: 155). La colección, que solo duró un año, prosiguió en la tarea de dar a conocer a los jóvenes emergentes o por emerger que habían colaborado en la revista; pues ahí se editaron seis volúmenes, entre los cuales figuran -además de los citados de Reyes y de la colección de dibujos de Benjamín Palencia titulada Niños-, si atendemos a los estrictamente poéticos, Signario, de Antonio Espina, y el referido Presagios, de Pedro Salinas. Y aunque no poético en puridad, debe sumarse a estos El cohete y la estrella, de José Bergamín, toda vez que sus aforismos tienen carácter de poesía enmascarada, según hace ver Nigel Dennis apoyándose en un juicio de Ramón Gaya (2008: iv). Estaba asimismo previsto, pero quedó pendiente, un volumen de Darío: Cartas y versos a Juan Ramón Jiménez.

También en lo tocante a la colección de libros Juan Ramón seguiría respirando por la herida (económica) y, de manera latente, por la de la ausencia de reconocimiento, que andando el tiempo haría más explícita. Así cuando le confiesa a su incondicional Guerrero Ruiz, en anotación de este

8. «La gente tarda mucho en pagar y es un conflicto constante, así que Juan Ramón ha hablado ya con Bergamín y hablará también a Reyes (que acaba de llegar) para hacer un nuevo arreglo. La recomendación del señor Ballester quedó hecha. El número de Índice saldrá dentro de unos días, se ha retrasado muchísimo por la cuestión económica y también por la ausencia de todos cuantos intervienen más o menos directamente en su producción» (Camprubí, 1006: 13). 
el 21 de febrero de 1931: «Sin dar en esta serie ninguno mío, perdí cuatro mil pesetas, y tanto de la revista como de la Biblioteca salieron ya algunos nombres con la reputación que hoy disfrutan para pasarse después a la Revista de Occidente» (Guerrero, 1998: 154). Por la fecha de la anotación -a los diez años de aparecida la revista-, ya era pronunciada la brecha entre el maestro de Moguer y los jóvenes a quienes había propulsado, y estos habían adquirido una presencia central en el escaparate de la literatura española. Solo un año después, la antología de Gerardo Diego -aunque verdaderamente coral y consultadafijaría el daguerrotipo socioliterario que Juan Ramón había contribuido a generar en 1921. Para justipreciar la importancia que tuvieron Índice y Juan Ramón Jiménez en la conformación de ese brillantísimo estado de cosas, basta echar la mirada hacia aquel año y considerar, no sin asombro, que por entonces los poetas que harían la transición desde el modernismo al esencialismo del 27 no habían publicado libros aún, no se conocían generalmente entre sí, no habían consolidado sus respectivas poéticas individuales y no tenían, en fin, ante sus ojos ni siquiera el vislumbre de lo que iban a ser'.

\section{Bibliografía citada}

Alonso D., Obras completas. 1: Poemas escogidos, Madrid, Gredos, 1993.

Camprubí Z., Epistolario I: cartas a Juan Guerrero Ruiz (1917-1956), eds. G. Palau de

Nemes y E. Cortés Ibáńez, Madrid, Residencia de Estudiantes, 2006.

Carrere E. (ed.), La corte de los poetas, Madrid, Librería de Pueyo, 1906.

Cossío J. M. de, "Recuerdos de una generación poética», en AA. VV., Homenaje universitario a Dámaso Alonso, Madrid, Gredos, 1970, pp. 189-202.

Dennis N., "José Bergamín, poeta», pról. a José Bergamín, Poesías completas I, ed. N. Dennis, Valencia, Pre-Textos, 2008, pp. iii-xiii.

Diego G. (ed.), Poesía española: antología 1915-1931, Madrid, Signo, 1932.

Díez de Revenga F. J., "Juan Ramón Jiménez y la “joven literatura” de los ańos veinte en España», en C. Cuevas García (ed.), Juan Ramón Jiménez: poesía total y obra en marcha, Barcelona, Anthropos, 1991, pp. 109-140.

Guemárez Cruz D., "Juan Ramón Jiménez, editor de la revista Índice», Bulletin of Hispanic Studies, 75 (1998), pp. 355-370.

Guerrero Ruiz J., Juan Ramón de viva voz (texto completo), vol. 1, ed. Manuel RuizFunes, Valencia, Pre-Textos / Museo Ramón Gaya, 1998.

Henríquez Jiménez A., «Un nonato número 5 de Índice, la revista de Juan Ramón Jiménez. Ecos de dos autores canarios. Rastreo del sumario del número 5», Philologica Canariensia, 10-11 (2004-2005), pp. 295-315.

Índice, edición facsímil, Madrid, José Esteban / El Museo Universal, 1987.

9. Solo a partir de 1924 puede hablarse de un cierto programa colectivo en la reformulación de la poesía española. En ese año comenzaron a pergeñarse los futuros homenajes gongorinos, y en ese año también la revista parisina Intentions publicó un número doble (23-24) dedicado a «La joven literatura espańola», coordinado por Valery Larbaud y, por la parte española, Antonio Marichalar, uno de los de Índice. 
Índice [en línea], Hemeroteca Digital de BNE: <http://hemerotecadigital .bne.es/details.vm?q=id:0003995067\&lang=es $>$ [consulta: 9 octubre 2013].

Molina C. A., Medio siglo de prensa literaria española (1900-1950), Madrid, Endymion, 1990.

Reyes A., Obras completas. 7: Cuestiones gongorinas, México D. F., Fondo de Cultura Económica, [1958] 1996.

- Obras completas. 24: Historia documental de mis libros, México D. F., Fondo de Cultura Económica, 1990.

Salinas P., Obras completas I (Poesía. Narrativa. Teatro), ed. E. Bou, Madrid, Cátedra, 2007.

Salinas P. \& J. Guillén, Correspondencia (1923-1951), ed. A. Soria Olmedo, Barcelona, Tusquets, 1992. 